\section{Determining historical distribution patterns of fur seals to aid management efforts in the Southern Ocean}

Determining how species distributions have changed due to human activity can be difficult without robust historical records. In the absence of such data, species distribution models can be used to predict where a species might have lived based on the environmental variables that support the species. The authors used satellite data of the Southern Ocean to predict the historical distribution patterns of Antarctic fur seals within the Commission for the Conservation of Antarctic Marine Living Resources (CCAMLR) to aid management efforts in the region.

One of the benefits of species distribution models is that they can show temporal shifts in a species' range, highlighting differences in activity during the annual cycle, for example. The authors tracked female Antarctic fur seals and used this information combined with sea ice concentrations, wind speed, sea surface temperature, and other data in species distribution models to predict where the species might have been found historically. The authors found that the foraging habitats of fur seal populations have been "relatively stable since 1993", despite notable changes to the physical environment in the Southern Ocean.

Next, predicted distribution patterns were overlaid on a map of CCAMLR fisheries management areas. The authors then calculated total fishing effort to determine the potential competition between fishers and fur seals. Female fur seals overlapped significantly with fisheries activities in several areas, suggesting a potential for competition for krill and other prey resources, particularly as the climate changes or if fisheries increase harvesting. The authors note, the "austral spring is an important period for females as it coincides with the increasing energetic demands of gestation [...] and reproductive success in the coming summer can be linked to prey availability at this time of year [...]. It is, therefore, a critical time for the monitoring of potential fisheries competition."

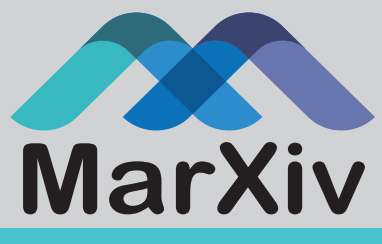

This is a summary of: Managing for change: Using vertebrate at sea habitat use to direct management efforts

Accessible at:

https://marxiv.org/nrfwb

Authors: Benjamin Arthur, Mark Hindell, Marthan Bester, P.J. Nico De Bruyn, Michael E. Goebel, Phil

Trathan, Mary-Anne Lea

Added to MarXiv:

May 2018

Published: Ecological Indicators, 2018

Suggested Citation: Determining historical distribution patterns of fur seals to aid management efforts in the Southern Ocean. OCTO (2018). DOI: 10.31230/osf.io/uxc7e

See more MarXiv summaries at https://www.marxivinfo.org/ summaries

Join the MarXiv Summaries monthly newsletter at https:// oct.to/marxivsum

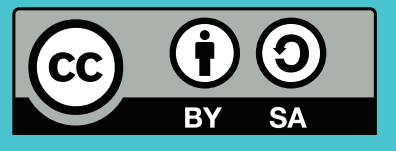

MarXiv is an ОСТO Initiative
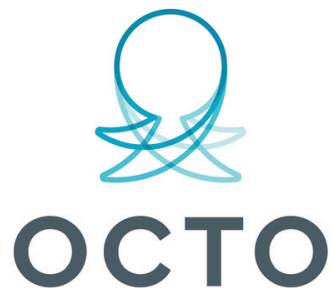

OPEN COMMUNICATIONS FOR THE OCEAN 